\title{
HUBUNGAN PELATIHAN DENGAN PERILAKU BIDAN DALAM MELAKUKAN PENCEGAHAN PENDARAHAN POSTPARTUM DI KABUPATEN BANTUL
}

\section{RELATIONSHIP OF TRAINING WITH THE BEHAVIOR OF MIDWIVES IN THE PREVENTION OF POSTPARTUM HEMORRHAGE AT BANTUL REGENCY}

\author{
Diah Nur Anisa $^{1 *}$, Detty S Nurdiati ${ }^{2}$, Wiwin Lismidiati ${ }^{3}$ \\ ${ }^{*}$ Universitas 'Aisyiyah Yogyakarta, Jl.Ringroad Barat Mlangi Nogotirto Gamping Sleman, \\ nursediahanisa@gmail.com, Indonesia \\ ${ }^{2}$ Universitas Gajah Mada, Jl. Farmako, Senolowo, Sekip Utara, Kec. Depok, Kabupaten Sleman, Daerah \\ Istimewa Yogyakarta 55281, email: dnurdiati@yahoo.com, Indonesia \\ ${ }^{3}$ Universitas Gajah Mada, Jl. Farmako, Senolowo, Sekip Utara, Kec. Depok, Kabupaten Sleman, Daerah \\ Istimewa Yogyakarta 55281, email: wiwien_lismidiati@ugm.ac.id, Indonesia
}

\begin{abstract}
Background: Postpartum hemorrhage is define as $500 \mathrm{cc}$ or more bleeding after the completion of third stage (after the placenta is born). Maternal mortality due to postpartum hemorrhage occurs a lot in health services, one of the factors that influence it is the behavior of health workers in the prevention of postpartum hemorrhage. The behavior of midwives in preventing postpartum hemorrhage is closely related to the competencies seen from the training attended.

Objective: To find out the relationship between training and the behavior of midwives in preventing postpartum hemorrhage in Bantul Regency.

Methods: We used a correlation study with a cross sectional design. The sampling technique in this study used probability sampling with cluster sampling totaling 68 midwives in five community health centers. Retrieval of data in this study used an observation sheet to see the actions of midwives in conducting active management in the third stage as a preventive measure for postpartum bleeding and the identity sheet of respondents to see the training that had been attended by midwives.

Results: There was no relationship between training with the behavior of midwives in the prevention of postpartum hemorrhage in Bantul Regency with a $p$ value of 0.093 . A total of 40 midwives $(58.8 \%)$ had good behavior and 53 midwives (77.9\%) had attended training.

Conclusion: There is no training relationship with the behavior of midwives in the prevention of postpartum hemorrhage in Bantul Regency
\end{abstract}

Keywords: Behavior, hemorrhage, postpartum, training

\section{PENDAHULUAN}

Angka kematian ibu merupakan salah satu target dalam MDGs lima yaitu menurunkan angka kematian maternal sebesar tiga per empat dari angka kematian maternal tahun 1999, sebanyak 450 per 100.000 menjadi 102 per 100.000 kelahiran bayi hidup pada tahun 2015. Penurunan angka kematian maternal masih terlalu lamban untuk mencapai target MDGs yang sudah hampir selesai. ${ }^{1}$

\section{World Health Organization (WHO)} menyatakan bahwa seharusnya 5,5\% pertahun terjadi penurunan angka kematian maternal, namun data WHO, UNICEF, UNFPA menunjukkan angka kematian ibu masih mengalami penurunan yang tidak sesuai target. Data menunjukkan 25-50\% kematian wanita usia subur di negara miskin disebabkan oleh masalah kehamilan, persalinan, dan nifas. Pada tahun 2015, WHO memperkirakan di seluruh dunia setiap tahunnya lebih dari 585 ibu hamil meninggal 
saat hamil dan bersalin. Di negara Indonesia jumlah angka kematian maternal yang belum mengalami penurunan secara signifikan, hal ini dilihat pada tahun 2015 terdapat 359 angka kematian maternal dan hanya turun sedikit dengan jumlah 305 kematian maternal pada tahun 2015. ${ }^{2}$ Penyebab utama kematian ibu adalah obstetri secara langsung yaitu pendarahan $28 \%$, preeklamsi atau eklamsi $24 \%$, infeksi $11 \%$, pada penyebab obstetri tidak langsung yaitu trauma obstetri $5 \%$, dan lain-lain $11 \%$.

Pendarahan postpartum adalah pendarahan $500 \mathrm{cc}$ atau lebih setelah selesainya kala III (setelah plasenta lahir). Jenis pendarahan postpartum dibagi dalam pendarahan dini apabila terjadi dalam 24 jam pertama pasca melahirkan dan pendarahan lambat bila pendarahan terjadi setelah 24 jam pasca melahirkan. Faktor-faktor yang mempengaruhi kejadian pendarahan postpartum adalah atonia uteri, partus lama, anemia, dan peregangan uterus yang berlebihan. $^{3}$ Sebagian besar kematian ibu karena PPH terjadi pada negara berkembang, di mana petugas kesehatan tidak mempunyai keterampilan yang baik dan kurang tersedianya peralatan dalam melakukan pencegahan pendarahan postpartum sehingga memberikan pelatihan keterampilan pada bidan diperlukan untuk meningkatkan kompetensi dalam melakukan pencegahan pendarahan postpartum. ${ }^{4}$ Pemerintah Indonesia telah mengupayakan memberikan pelatihan wajib bagi petugas kesehatan untuk menolong persalinan, di antaranya asuhan persalinan normal.

Menurut profil kesehatan Kabupaten Bantul, angka kematian lbu mengalami peningkatan dibandingkan tahun 2015, jika pada tahun 2016 sebesar 97,65/100.000 Kelahiran Hidup yaitu sejumlah 12 kasus, sedangkan pada tahun 2015 sebanyak 11 kasus sebesar 87,5/100.000. Hasil Audit Maternal Perinatal (AMP) menyimpulkan bahwa penyebab kematian ibu pada tahun 2016 adalah Pre Eklampsia Berat (PEB) sebanyak 33\% (4 kasus), Pendarahan sebesar 17\% (2 kasus), Gagal Jantung 17\% (2 kasus), Sepsis 17\% (2 kasus), dan Lainnya $\quad 16 \% \quad(2$ kasus $){ }^{5} \quad$ Kejadian pendarahan postpartum erat kaitannya dengan kompetensi yang dilihat dari pelatihan yang diikuti bidan. Dengan adanya pelatihan yang diikuti bidan diharapkan dapat memberikan pelayanan obstetri neonatal, khususnya mampu memberikan ketrampilan yang sesuai standar sebagai tindakan pencegahan perdarahan postpartum. ${ }^{6}$ Dengan hal tersebut, peneiti ingin melakukan penelitian tentang hubungan pelatihan dengan perilaku bidan dalam melakukan pencegahan pendarahan postpartum di Kabupaten Bantul. Tujuan penelitian ini untuk mengetahui hubungan pelatihan dengan perilaku bidan dalam melakukan pencegahan pendarahan postpartum di Kabupaten Bantul.

\section{BAHAN DAN CARA PENELITIAN}

Hubungan Pelatihan dengan Perilaku Bidan dalam Melakukan Pencegahan Perdarahan Postpartum di Kabupaten Bantul 
Penelitian ini dilaksanakan pada bulan Oktober sampai Desember 2016 di Puskesmas Banguntapan II, Puskemas Pleret I, Puskesmas Bambanglipuro, Puskesmas Sanden, dan Puskesmas Imogiri I. Penelitian ini termasuk jenis penelitian korelasi dengan rancangan cross sectional. Teknik sampling pada penelitian ini menggunakan probability sampling dengan cluster sampling berjumlah 68 bidan pada lima Puskesmas.

Pengambilan data pada penelitian ini menggunakan lembar observasi untuk melihat tindakan bidan dalam melakukan manajemen aktif kala III sebagai tindakan pencegahan pendarahan postpartum. Selain itu Peneliti juga menggunakan lembar identitas responden untuk melihat pelatihan yang telah diikuti oleh bidan. Observasi pencegahan pendarahan postpartum ini dilakukan oleh asisten peneliti. Asisten peneliti merupakan perawat yang ikut membantu proses persalinan.

Tabel 1 menunjukkan karakteristik responden penelitian yaitu seluruh bidan yang bekerja di Puskesmas Banguntapan II, Imogiri I, Bambanglipuro, Sanden, dan Pleret I. Karakteristik responden pada penelitian ini terdiri dari 1) Usia; 2) Pendidikan; 3) Masa Kerja. Berdasarkan hal tersebut diperoleh hasil bahwa respoden rata-rata berusia 3645 tahun yang berjumlah 31 bidan (45.56\%), dengan pendidikan D3 sebanyak 53 bidan
(70.95\%), dengan lama kerja 6-10 tahun sebanyak 21 bidan (30.88\%).

Tabel 1. Hasil distribusi karakteristik responden berdasarkan usia, pendidikan dan lama kerja $(\mathbf{n}=68)$

\begin{tabular}{llll}
\hline No & Karakteristik & \multicolumn{2}{c}{ Frekuensi } \\
\cline { 3 - 4 } & & $\mathbf{N}$ & $\%$ \\
\hline $\mathbf{1}$ & Usia & & \\
& a. $26-35$ tahun & 18 & 26.47 \\
& b. $36-45$ tahun & 31 & 45.59 \\
& c. $46-55$ tahun & 18 & 26.47 \\
& d. $56-65$ tahun & 1 & 1.47 \\
\hline $\mathbf{2}$ & Pendidikan & & \\
& a. D1 & 7 & 10.29 \\
& b. D3 & 53 & 77.95 \\
& c. S1/D4 & 8 & 11.76 \\
\hline $\mathbf{3}$ & Lama Kerja & & \\
& a. $\leq 5$ tahun & 0 & 0 \\
& b. 6-10 tahun & 21 & 30.88 \\
& c. 11-15 tahun & 16 & 23.52 \\
& d. 16-20 tahun & 13 & 19.12 \\
& e. >20 tahun & 18 & 26.48 \\
\hline
\end{tabular}

Sumber: Data Primer 2016

Tabel 2: Distribusi Frekuensi perilaku Bidan di Puskesmas Banguntapan II, Pleret I, Imogiri I

Bambanglipuro, dan Sanden SeptemberDesember $2016(n=68)$

\begin{tabular}{cccc}
\hline \multirow{2}{*}{ Variabel } & & \multicolumn{2}{c}{ Frekuensi } \\
\cline { 2 - 4 } & & $\mathbf{N}$ & $\%$ \\
\hline Perilaku & Baik & 40 & 58.8 \\
\cline { 2 - 4 } & Kurang & 28 & 41.2 \\
\hline Total & & 68 & 100 \\
\hline
\end{tabular}

Tabel 2 menunjukkan distribusi frekuensi perilaku bidan dalam melakukan pencegahan pendarahan postpartum. Tabel tersebut menunjukkan bahwa rata-rata bidan mempunyai perilaku baik sebanyak 40 bidan (58.8\%).

Tabel 3 menunjukkan distribusi frekuensi pelatihan yang diikuti bidan dalam melakukan pencegahan pendarahan postpartum . Tabel tersebut menunjukkan bahwa rata-rata bidan telah mengikuti pelatihan minimal $1 \mathrm{x}$ sebanyak 55 bidan (77.9\%) 
Tabel 3 Distribusi Frekuensi Pelatihan Bidan di Puskesmas Banguntapan II, Pleret I, Imogiri I Bambanglipuro dan Sanden SeptemberDesember $2016(n=68)$

\begin{tabular}{cccc}
\hline \multirow{2}{*}{ Variabel } & \multicolumn{2}{c}{ Frekuensi } \\
\cline { 2 - 4 } Pelatihan & Belum Pernah & $\mathbf{N}$ & $\%$ \\
\cline { 2 - 4 } & $\geq 1 \times$ pelatihan & 53 & 22 \\
\hline Total & & 68 & 100 \\
\hline
\end{tabular}

Tabel 4. Uji Bivariate di Puskesmas

Banguntapan II, Pleret I, Imogiri I

Bambanglipuro, dan Sanden SeptemberDesember $2016 \quad(n=68)$

\begin{tabular}{|c|c|c|c|c|c|c|c|}
\hline & \multicolumn{4}{|c|}{ Perilaku } & \multirow{3}{*}{ OR } & \\
\hline & & \multicolumn{2}{|c|}{ Baik } & \multicolumn{2}{|c|}{ Kurang } & & $p$ \\
\hline & & $\mathbf{N}$ & $\%$ & $\mathbf{N}$ & $\%$ & & va \\
\hline \multirow[t]{3}{*}{$\begin{array}{l}\text { Pelat } \\
\text { ihan }\end{array}$} & $\begin{array}{l}\geq 1 \mathrm{x} \\
\text { pelatihan }\end{array}$ & 34 & 85 & 19 & 67.8 & $\begin{array}{l}2.68 \\
4\end{array}$ & $0.0 s$ \\
\hline & $\begin{array}{l}\text { Belum } \\
\text { Pelatihan }\end{array}$ & 6 & 15 & 9 & 32.2 & & \\
\hline & Total & 40 & 100 & 28 & 100 & & \\
\hline
\end{tabular}

Tabel 4 menunjukkan hubungan pelatihan dengan perilaku bidan dalam melakukan pencegahan pendarahan postpartum di Puskesmas Banguntapan II, Pleret I, Imogiri I Bambanglipuro, dan Sanden. Dari hasil tersebut diperoleh bahwa 34 (85\%) mempunyai perilaku baik meskipun belum pernah mendapatkan pelatihan, sedangkan terdapat $6 \quad(15 \%)$ bidan mempunyai perilaku baik dan sudah mendapatkan pelatihan $>1 \mathrm{x}$. Hasil uji didapatkan nilai $p$ value $>0,05$ yaitu 0,093 dengan kesimpulan tidak terdapat hubungan pelatihan dengan perilaku bidan dalam melakukan pencegahan pendarahan postpartum .

Pendarahan postpartum menjadi penyebab utama kematian ibu pada sebagian besar negara-negara berpenghasilan rendah. Pendarahan postpartum pada umumnya didefinisikan sebagai kehilangan darah $500 \mathrm{ml}$ atau lebih dalam waktu 24 jam setelah lahir. Pendarahan postpartum berat didefinisikan sebagai kehilangan darah $1000 \mathrm{ml}$ atau lebih dalam jangka waktu 24 jam pertama atau lebih. ${ }^{6}$

Untuk mengurangi angka kematian akibat pendarahan postpartum, diperlukan kerja sama antara masyarakat, LSM, $p$ Pemerintah, dan penyedia layanan 093kesehatan dengan memastikan bahwa tenaga kesehatan mempunyai keterampilan yang baik terutama pada daerah pedesaan dengan akses kesehatan yang memadai. ${ }^{7}$

Pendidikan bidan erat kaitannya dengan pelatihan yang diikuti oleh bidan. Hasil penelitian ini menyatakan bahwa bidan yang minimal melakukan 1 kali pelatihan lebih banyak mempunyai perilaku yang baik dalam melakukan pencegahan pendarahan postpartum dibandingkan dengan bidan yang belum pernah mengikuti pelatihan. Hal ini sejalan dengan penelitian Azani yang menyatakan bahwa bidan yang pernah mengikuti pelatihan APN (Asuhan Persalinan Normal) akan mempunyai perilaku tepat dalam penatalaksanaan rujukan pada kasus pendarahan postpartum di RSUD Arifin Ahmad Pekanbaru. ${ }^{8}$

Hasil pada penelitian ini menyatakan bahwa tidak ada hubungan signifikan antara pelatihan dengan perilaku bidan dalam melakukan pencegahan pendarahan 
postpartum, namun terlihat bahwa bidan yang minimal melakukan pelatihan $1 \mathrm{x}$ menunjukkan perilaku yang baik sedangkan bidan yang belum melakukan pelatihan menunjukkan perilaku yang kurang baik. Hal ini sejalan dengan penelitian Sulistiani (2014) yang menyatakan bahwa pelatihan APN mempunyai pengaruh yang signifikan terhadap pengetahuan dan keterampilan bidan dalam melakukan manajemen aktif kala 3 dengan nilai $p$ value 0.000 (signifikan). Sebanyak 29 bidan dari total 33 bidan yang mengikuti pelatihan APN mempunyai keterampilan yang baik. ${ }^{9}$ Sesuai dengan penelitian Kato, menyatakan bahwa perlu diadakannya pemberian pelatihan dengan cara memberikan simulasi untuk meningkatkan pengetahuan tentang pencegahan pendarahan postpartum. Pada penelitian Kato terlihat bahwa bidan yang diberikan simulasi pencegahan pendarahan postpartum akan mengalami peningkatan pengetahuan dalam melakukan pencegahan pendarahan postpartum. ${ }^{10}$

Hofmeyr dan Qureshi yang menyatakan bahwa pencegahan kematian akibat pendarahan postpartum membutuhkan adanya sistem keluarga yang efektif terkait dengan pemilihan tempat bersalin sesuai dengan ketersediaan sarana dan prasarana, selain itu diperlukan adanya infrastruktur dan kemudahan mengakses fasilitas kesehatan. Tindakan pencegahan untuk pendarahan postpartum meliputi manajemen aktif kala III, pemberian medikasi, dan tindakan lainnya.
Dengan hal tersebut, perlu adanya pelatihan untuk semua petugas kesehatan yang membantu dalam proses persalinan untuk memastikan bahwa tenaga kesehatan tersebut mempunyai kompetensi dalam menolong persalinan. ${ }^{11}$ Dalam penelitian ini masih terdapat 15 bidan pada lima puskesmas di Kabupaten Bantul yang belum pernah mengikuti pelatihan tentang pertolongan persalinan. Hasil penelitian ini sejalan dengan penelitian Runtu yang menyimpulkan bahwa tidak ada hubungan yang signifikan antara pelatihan yang diikiuti dengan perilaku perawat dalam menerapkan universal precaution di RSUP Prof.Dr.R. Kandou Manado. Hasil pengamatan peneliti bahwa masih terdapat perilaku yang buruk pada bidan yang sudah mengikuti pelatihan pertolongan persalinan, hal ini kemungkinan dikarenakan bidan kembali ke pola kerja rutinitas sehingga untuk merubah suatu kebiasaan merupakan hal yang tidak mudah. $^{12}$

Menurut asumsi peneliti, hal ini dapat menjadi kendala bagi fasilitas kesehatan dalam menghadapi pencegahan pendarahan postpartum dikarenakan masih terdapat bidan yang belum mempunyai kompetensi yang cukup dalam melakukan pertolongan persalinan.

\section{KESIMPULAN}

Berdasarkan uraian pada hasil penelitian dapat disimpulkan bahwa tidak ada hubungan pelatihan dengan perilaku bidan 
dalam melakukan pencegahan pendarahan postpartum di Kabupaten Bantul. Namun, penelitian ini menunjukkan bahwa bidan yang mengikuti pelatihan lebih banyak mempunyai perilaku yang baik daripada bidan yang belum mengikuti pelatihan. Saran pada penelitian ini diharapkan peneliti lain dapat mengetahui faktor lama kerja bidan, sehingga mengetahui faktor lain yang mempengaruhi perilaku bidan.

\section{TERIMA KASIH}

1. Ibu Warsiti, M.Kep Sp Kep Mat, Rektor UNISA, JI Ringroad Barat Mlangi, Nogotirto Gamping Sleman, wwww.unisa.ac.id

2. Ibu Suratini,M.Kep.,Sp.Kep.Kom Selaku Ketua Prodi IImu Keperawatan Universitas ‘Aisyiyah Yogyakarta

\section{KEPUSTAKAAN}

1. Kementerian Kesehatan Republik Indonesia. (2016). Laporan Tahunan Ditkesga Kemenkes RI. Laporan.

2. World Health Organization. (2015). World Health Statistics 2015.

3. Ngwenya,S. (2016). Postpartum hemorrhage: incidence, risk factors, and outcomes in a low-resource setting. Dovepress: Open access to scientific and medical research

4. Lalonde, A. (2012). Prevention and treatment of postpartum hemorrhage in low-resource settings. International Journal of Gynecology and Obstetrics, 117(2), 108-118. https://doi.org/10.1016/j.ijgo.2012.03.001

5. Dinas Kesehatan Kabupaten Bantul.
(2017). Profil kesehatan Kabupaten Bantul 2017

6. Nawangsari,H. (2009). Hubungan Penguasaan Kompetensi Asuhan Persalinan Normal (APN) dengan pengetahuan dan sikap bidan dalam melaksanakan Pertolongan Persalinan Normal di Kabupaten Jombang Jawa Timur. Indonesian Journal of Obstetry and Gynechology

7. Lalonde, A. (2012). Prevention and treatment of postpartum hemorrhage in low-resource settings. International Journal of Gynecology and Obstetrics, 117(2), 108-118. https://doi.org/10.1016/j.ijgo.2012.03.001

8. Walraven.,GMD, MPH, PhD. (2009). Management of post-partum hemorrhage in low-income countries. Best Practice \& Research Clinical Obstetrics and GynaecologyVol. 22, No. 6, 2008 https://doi.org/10.1016/j.bpobgyn.2008.08 .002

9. Azani,D. (2012). Hubungan Pelatihan Asuhan Persalinan Normal (APN) Dengan Ketepatan Penatalaksanaan Rujukan Pada Kasus Perdarahan Postpartum Di RSUD Arifin Achmad Pekanbaru Tahun 2012. Akbid 165 Pekan Baru

10. Sulistiani,A. (2014). Pengaruh Pelatihan Asuhan Persalinan Normal terhadap Kompetensi Bidan tentang Manajemen Aktif Kala III Persalinan Kabupaten Boyolali. Akademi Kebidanan Estu Utomo

11. Mrcog, G. J. H. (2008). Misoprostol for the prevention and treatment of postpartum haemorrhage. 22(6), 10251041

https://doi.org/10.1016/j.bpobgyn.2008.08 .005

12. Runtu,L. (2012). Faktor-faktor yang berhubungan dengan perilaku perawat dalam penerapan. Progam Studi IImu Kesehatan Masyarakat Progam Pasca Sarjana Universitas Gajah Mada Yogyakarta 